\title{
As Etimologias de Giovanni Boccaccio
}

Pedro F. Heise*

RESUMO: Seguindo o preceito amplamente difuso na Idade Média de que "nomina sunt consequentia rerum", Boccaccio nomeou suas obras de acordo com significados etimológicos, sobretudo de origem grega, às vezes com acepções criadas pelo próprio autor. Além dos títulos, os nomes dos personagens principais de quase toda sua produção literária também foram forjados segundo certas etimologias. Dentre os inúmeros casos apresentados pelo autor do Decameron, um se destaca: trata-se da origem do vocábulo "poeta", demonstrada por Boccaccio em algumas de suas obras pós-decameronianas, a saber, a Genealogia deorum gentilium, o Trattatello in laude di Dante e as Esposizioni sopra la Comedia di Dante. Como se verá neste artigo, Boccaccio propôs mais de uma etimologia para "poeta", provavelmente devido à polêmica cristã que julgava a poesia contrária à verdade, de modo que o poeta, que era um "fazedor de fábulas", era considerado um mentiroso. Boccaccio, ao rebater essa afirmação, defende o lugar do poeta na sociedade de seu tempo, demonstrando a necessidade da poesia para o homem.

PALAVRAS-CHAVE: Boccaccio; etimologia; poesia; mentira.

ABSTRACT: Seguendo il precetto molto diffuso nel Medioevo che dice "nomina sunt consequentia rerum”, Boccaccio intitolò le sue opere in conformità a

*Pós-doutorando (bolsista Fapesp) junto à Área de Língua e Literatura Italiana da Faculdade de Filosofia, Letras e Ciências Humanas - USP 
significati etimologici, soprattutto di origine greca, a volte con accezioni create dall'autore. Oltre ai titoli, anche i nomi dei personaggi principali di quasi tutta la sua produzione letteraria sono stati forgiati secondo certe etimologie. Fra i numerosi casi presentati dall'autore del Decameron, ne risalta uno: si tratta dell'origine del vocabolo "poeta", dimostrata da Boccaccio in alcune delle sue opere posteriori al Decameron, la Genealogia deorum gentilium, il Trattatello in laude di Dante e le Esposizioni sopra la Comedia di Dante. Come si vedrà in questo articolo, Boccaccio propose più di una etimologia per "poeta", probabilmente a causa della polemica cristiana che considerava la poesia contraria alla verità, e per questo il poeta era ritenuto "artefice di favole", ossia un bugiardo. Boccaccio si contrappone a questa affermazione e difende il ruolo del poeta nella società del suo tempo, dimonstrando la necessità della poesia per l'uomo.

PAROLE CHIAVE: Boccaccio; etimologia; poesia; bugia.

ABSTRACT: Following the precept of the Middle Age about "nomina sunt consequentia rerum", Boccaccio named his works with etymological meanings, especially from Greek, sometimes created by himself. The name of some characters also had certain etymologies. Among the numerous cases presented by the author of the Decameron there is one to our interest: the origin of the word "poet", demonstrated by Boccaccio in some of his post decameronian works: Genealogia deorum gentilium, Trattatello in laude di Dante and Esposizioni sopra la Comedia di Dante. As it is possible to see in this article, Boccaccio proposed more than one etymology to "poet", probably because of the Christian polemic who judge poetry contrary to the truth, so that poet, who was a "maker of fables", was considered a liar. Boccaccio, contesting this statement, defends the place of the poet in the society of his time, showing the necessity of poetry to humanity.

KEY WORDS: Boccaccio; etymology; poetry; lie. 


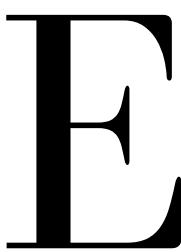

m um artigo publicado no primeiro volume do periódico Studi sul Boccaccio, Agostino Pertusi revela que "muitos estudiosos das obras latinas de Boccaccio exprimiram juízos duros em relação às suas etimologias, falando de 'besteiras', de 'derivações impossíveis', de "explicações estranhas'” (PERTUSI, 1963, p. 363, tradução nossa). Pertusi acrescenta que, geralmente, os "erros" etimológicos das palavras gregas haviam sido atribuídos a Leôncio Pilato, um professor calabrês de quem Boccaccio ouvia os versos da Ilíada e da Odisseia traduzidos diretamente do original para o latim.

O texto de Pertusi, porém, se limita a analisar as etimologias gregas nas obras eruditas de Boccaccio, como se lê no título de seu texto; por obras eruditas, no caso de Boccaccio, entendese sua produção em língua latina posterior ao Decameron. Assim, todas as obras do período 
anterior ficaram de fora do estudo de Pertusi. Mas cabe recordar que também nas obras da juventude Boccaccio empregou etimologias de origem grega, tanto para dar títulos a elas como para caracterizar seus personagens. E isto mesmo antes de conhecer o professor calabrês, o que ocorreu provavelmente apenas em 1359 (SURDICH, 2001, p. 266), ou seja, quase uma década após a conclusão da primeira versão do Decameron. Seguem abaixo alguns exemplos de como Boccaccio trabalhava com as etimologias em suas composições literárias.

Considerada uma de suas primeiras obras, o Filostrato, composto por volta de 1335, é narrado pelo personagem do mesmo nome do título. Seu nome é explicado no subtítulo: "Filostrato è il titolo di questo libro, e la cagione è questa: per ciò che ottimamente si confà con l'effetto del libro. Filostrato tanto viene a dire quanto uomo vinto e abbattuto d'amore; come veder si può che fu Troiolo dall'amor vinto sì ferventemente amando Criseida e sì ancora nella sua partita". É de se notar, antes de tudo, a presença do preceito, amplamente difuso na Idade Média, do "nomina sunt consequentia rerum" na frase "per ciò che ottimamente si confà con l'effetto del libro"; ou seja, o nome do protagonista indica as consequências que ele sofrerá.

Quanto à etimologia, para Boccaccio "filos" significa "amor", enquanto "stratos" seria o "vencido", o "derrotado", o que parece ser sugerido pelo significado que encontramos em dicionários modernos da língua grega que nos apresentam a tradução de "stratos" como "exército". Segundo o Vocabolario della lingua greca, de Franco Montanari, "filostratos" seria, portanto, o "amigo dos soldados". Para além do dicionário, Filóstrato é nome de personagem em Xenofontes, Aristófanes e Plutarco, fato que deve ter levado Boccaccio a empregá-lo em sua obra. Além disto, deve ser lembrado que Petrarca havia escrito uma "belíssima comédia, a que deu o título de Filóstrato", conforme narra Boccaccio no De vita et moribus domini Francisci Petracchi (§ 28, ed. Villani).

Daquele mesmo período, cerca de 1336 a 1338, Boccaccio compôs o Filocolo, um dos primeiros romances escritos em "volgar lingua", no qual introduz a figura de Fiammetta, a musa do poeta que estará presente em quase todas as suas outras obras. No terceiro livro do Filocolo, no capítulo 75, Florio, o protagonista das histórias contadas pelo narrador a pedido de Fiammetta, decide mudar seu nome para Filocolo (daqui o título da obra) devido à situação por que passava: os sofrimentos causados pelo amor. Vemos, mais uma vez, o emprego do preceito "nomina sunt consequentia rerum". É isto que explica minuciosamente o próprio personagem (III 75, 5-6): 
E certo tal nome assai meglio che alcuno altro mi si confà, e la ragione per che, io la vi dirò. Filocolo è da due greci nomi composto, da "philos" e da "colon"; e "philos" in greco tanto viene a dire in nostra lingua quanto "amore" e "colon" in greco similemente tanto in nostra lingua risulta quanto "fatica": onde congiunti insieme, si può dire, trasponendo le parti, fatica d'amore. [...] Sì che, chiamandomi questo nome, l'effetto suo s'adempierà bene nella cosa chiamata [...].

"Filos", como já vimos, é o "amor" para Boccaccio; quanto a "colon", o que encontramos de mais próximo a este termo no já citado Vocabolario della lingua greca foi "colos", que significa "bile", e que por extensão pode significar "tristeza", "melancolia"; o significado dado por Boccaccio, "fatica d'amore", é expressão difícil de se traduzir em português, mas talvez no "fatica" haja um pouco de melancolia ou tristeza por parte de Florio e Biancifiore (representados pelo narrador e por Fiammetta), pois, apesar de se amarem, alcaçam a união apenas depois de muitas "fatiche".

Também sua obra maior, o Decameron, possui título inspirado diretamente na língua grega: "deca", significa "dez", e "meron", que Boccaccio derivou de "hêmera", significa "dias"; de fato, como é sabido, as novelas são contadas em dez dias. Ao apresentar a "onesta brigata", o narrador omite os nomes reais dos "novellatori" (Decameron, Introdução ao primeiro dia, § 50, ed. Branca):

Li nomi delle quali [das narradoras] io in propria forma racconterei, se giusta cagione da dirlo non mi togliesse, la quale è questa: che io non voglio che per le raccontate cose da loro, che seguono, e per l'ascoltate nel tempo avvenire alcuna di loro possa prender vergogna.

Dar novos nomes, aliás, não deixa de ser uma forma de batismo, o que é coerente com a ideia do escritor que pretendia criar uma nova sociedade a partir da desolação causada pela peste em 1348. Assim, seguindo o preceito em voga, conforme explica Luigi Sasso, "Boccaccio quer dar aos personagens do grupo nomes significativos e reveladores do caráter e das qualidades que cada narrador assumirá ao longo dos dez dias" (SASSO, 1980, p. 156, tradução nossa); mas o significado de seus nomes, Boccaccio, como bom escritor, não o revela de forma ingênua. Caberá ao leitor desvendar a relação dos nomes com seus personagens, sempre lembrando do "nomina sunt consequentia rerum". 
Passando ao período das obras eruditas, uma delas nos interessa neste momento em particular, a Genealogia deorum gentilium. Justamente por se tratar de uma "genealogia", essa obra é repleta de explicações etimológicas, como o nome do primeiro deus de todos os deuses, Demogorgom, que é constituído, como explica Boccaccio, de "demo" e "gorgom", isto é, "demon 'deus', como diz Leôncio, e gorgon que significa 'terra'" (Genealogia 1, proêmio, tradução nossa). Além disto, Demogorgom era "horrível por seu próprio nome" (ibidem). ${ }^{1}$ Este é apenas um exemplo das várias etimologias que Boccaccio apresenta durante o livro todo.

No que diz respeito às obras eruditas, Pertusi, no artigo citado, distinguiu três fontes das etimologias gregas de Boccaccio: a) aquelas atribuídas explicitamente a Leôncio Pilato, como a que acabamos de ver; b) aquelas atribuídas a autores latinos clássicos, como Cícero, Macróbio, Varrão, Sérvio, Fulgêncio, e medievais, como Anselmo, Paulo Perusino e certo Teodôncio, personagem em relação ao qual a crítica até hoje não conseguiu avançar, pois apenas na obra de Boccaccio encontra-se seu nome; e, por fim, c) aquelas que Boccaccio apresenta como próprias (PERTUSI, 1963, p. 364). Mas, como veremos, é necessário acrescentar outra fonte e da maior importância para nosso estudo: Francesco Petrarca.

Em três obras do período pós-decameroniano, na Genealogia deorum gentilium, no Trattatello in laude di Dante e nas Esposizioni sopra la Comedia di Dante, Boccaccio comenta a polêmica que havia naquela época quanto à origem dos termos "poeta" e "poesia", pois parecia haver uma certa ligação destes nomes com "mentiroso" e "mentira". Assim, Boccaccio compõe uma breve história da poesia, que passamos a descrever de forma resumida: "A primeira gente nos primeiros séculos, apesar de muito rude e inculta, desejou extremamente conhecer a verdade por meio do estudo, tal como ainda vemos ser o desejo de todos por natureza" (Trattatello 1, 128, tradução nossa). Em seguida, observando os movimentos da natureza, aquela "primeira gente" imaginou que tudo deveria proceder de uma potência divina, a qual chamaram "divindade"; a fim de cultivar esta divindade, a "primeira gente" propôs a construção de "templos"; os que deveriam servir nestes templos teriam de ser sagrados, homens dignos de se reverenciar, que foram chamados de "sacerdotes"; além disso, a "primeira gente" fez várias representações das divindades, com estátuas, vasos, vestimentas; seguindo esse raciocínio, a "primeira gente" não poderia render graças a essas divindades com um estilo qualquer, conforme se lê nos parágrafos 130-132 do Trattatello:

1 Quanto ao nome do primeiro deus da Genealogia, houve críticos que acusaram uma falha de Boccaccio, que teria confundido o "demiurgo" do Timeu de Platão com "demogorgom"; cf. introdução de Jon Solomon (2011, p. XXIV). 
E, acciò che a questa cotale potenzia tacito onore o quasi mutolo non si facesse, parve loro che con parole d'alto suono essa fosse da umiliare e alle loro necessità rendere propizia. E così come essi estimavano questa eccedere ciascuna altra cosa di nobilità, così vollono che, di lunghi da ogni plebeio o publico stilo di parlare, si trovassero parole degne di ragionare dinanzi alla divinità, nelle quali si porgessero sacrate lusinghe. E oltre a questo, acciò che queste parole paressero avere più d'efficacia, vollero che fossero sotto legge di certi numeri composte, per li quali alcuna dolcezza si sentisse, e cacciassesi il rincrescimento e la noia. E certo, questo non in volgar forma o usitata, ma con artificiosa e nuova convenne che si facesse. La quale forma li Greci appellano poetes; laonde nacque, che quello che in cotale forma fatto fosse s'appellasse poesis; e quegli, che ciò facessero o cotale modo di parlare usassono, si chiamassero "poeti".

Também na Genealogia, no sétimo capítulo do penúltimo livro, Boccaccio explica, mais uma vez, a etimologia do termo "poesia", seguindo a versão do Trattatello: poesia não vem de "poio, pois", que significa "fingo, fingis", mas vem de "poetes", um antiquíssimo vocábulo dos gregos que em latim significa "exquisita locutio", um discurso excelente.

Já nas anotações que fez para suas lecturae dantis, hoje recolhidas em volume sob o título Esposizioni sopra la Comedia di Dante, Boccaccio, na explicação ao primeiro canto do Inferno, retoma a discussão sobre a origem do termo "poeta". Alguns invejosos diziam, conta Boccaccio, que o nome "poeta" vinha de um verbo dito "poio, pois", o qual, conforme querem os gramáticos, quer dizer o mesmo que "fingo, fingis"; esse "fingo" tem várias acepções, pois pode ser "compor", “ornar", "mentir” e outras coisas ainda (canto 1, esposizione litterale, 71):

Quegli adunque che dall'avilire altrui credono sé essaltare dissono e dicono che dal detto verbo "poio" viene questo nome "poeta"; e per ciò che quello suona "poio" che "fingo", lasciati stare gli altri significati di "fingo", e preso quel solo nel quale egli significa "mentire", conchiudendo, vogliono che "poeta" e "mentitore" sieno una medesima cosa: e per questo sprezano e aviliscono e anullano in quanto possono i poeti, ingegnandosi, oltre a questo, di scacciargli e di sterminargli del mondo, nel cospetto del non intendente vulgo gridando i poeti per autorità di Platone dovere esser cacciati delle città. 
Boccaccio nega, assim, a etimologia que liga o verbo grego poio, pois ao verbo latino fingo, fingis, o que não é de se admirar, pois a poesia, perante os cristãos, deveria dizer apenas a verdade. Um outro modo de explicar a rejeição da etimologia correta seria lembrar que naquela época praticamente ninguém sabia grego; o problema dessa explicação, contudo, é que se sabe que foi justamente Boccaccio o responsável pela criação da primeira cátedra dessa língua na universidade de Florença, apresentando o excêntrico professor calabrês Leôncio Pilato (Genealogia 15, 7).

Como justificar, então, a insistência de Boccaccio em empregar uma etimologia falsa? Em primeiro lugar, isto mostra a persistência em negar a associação do poeta como compositor de "fabulae", no sentido de mentiras; em segundo, revela a posição do autor em relação a outros poetas que defendiam seus trabalhos, e, neste caso, mostra alinhar-se a seu "pai e mestre", Francesco Petrarca.

A propósito de Petrarca, também nas Esposizioni Boccaccio recorre ao poeta do Canzoniere e menciona explicitamente a epístola deste ao irmão Gherardo, a Familiares número 4 do livro 10 (ed. Rossi-Bosco). A intenção do poeta era mostrar ao irmão, que tinha se tornado membro da ordem dos cartuxos, de que não havia problema em ler poesia, pois até mesmo a teologia era uma "poesia de Deus". Nas suas palavras, Petrarca diz (Familiarium rerum libri 10, 4): "A teologia não é nem um pouco inimiga da poesia. Ficas admirado? Pouco falta para que eu diga que a teologia é a poesia de Deus: chamar Cristo ora leão, ora cordeiro, ora verme, o que é senão poesia?" (tradução nossa).

É por isso que Boccaccio, no Trattatello, retoma a concepção de Petrarca (Trattatello 1, 154, tradução nossa):

[...] a teologia e a poesia podem se dizer quase uma coisa, pois o conteúdo é o mesmo; aliás, digo que a teologia nada mais é senão uma poesia de Deus. E que outra coisa é senão ficção poética na Escritura dizer que Cristo é ora leão, ora cordeiro, ora verme, às vezes dragão, às vezes pedra, e outros muitos modos [...]?”

Veja-se, então, que até os exemplos são os mesmos, mas Boccaccio, conforme seu próprio estilo, os amplia (a amplificatio), acrescentando seres míticos (dragão), seres inanimados (pedra) e "outros muitos modos".

Pertusi conclui seu artigo afirmando que "rir dessas e de outras invenções desse tipo não 
tem sentido; falar de absurdos ou de besteiras é colocar-se fora da história, e para Leôncio, em particular, fora da história da etimologia junto aos bizantinos e aos ítalo-gregos do sul da Itália" (PERTUSI, 1963, p. 384, tradução nossa). Nós acrescentamos que rir de Boccaccio significa rir de alguém que já estava rindo antes de nós, de modo que nosso riso se torna patético, presunçoso e sem sentido; falar das tais "besteiras" em relação a Boccaccio é não levar em conta o elemento fundamental da arte do poeta: a ficção.

\section{Referências bibliográficas}

BOCCACCIO, G. Genealogia deorum gentilium. (Org. V. Romano). Roma-Bari: Laterza, 1951.

BOCCACCIO, G. Genealogy of the pagan gods. (Org. e trad. J. Solomon, vol. 1, livros 1-5). London: Harvard, 2011.

BOCCACCIO, G. Decameron. (Org. V. Branca). Milano: Einaudi, 1992.

BOCCACCIO, G. Esposizioni sopra la Comedia di Dante.(Org. G. Padoan). Milano: Mondadori, 1994.

BOCCACCIO, G. Vite di Dante. (Org. P. G. Ricci). Milano: Mondadori, 2002.

BOCCACCIO, G. Vita di Petrarca. (Org. G. Villani). Roma: Salerno, 2004.

MONTANARI, F. Vocabolario della lingua greca. Torino: Loescher, 1995.

PERTUSI, A. Le etimologie greche nelle opere erudite del Boccaccio. Studi sul Boccaccio, v. 1, p. 363-385, 1963

PETRARCA, F. Opere. (Org. Rossi-Bosco). Milano: Sansoni, 1993.

SASSO, L. L' “interpretatio nominis”. Studi sul Boccaccio, v. 12, p. 129-174, 1980.

SURDICH, L. Boccaccio. Roma-Bari: Laterza, 2001. 